\title{
Control de Garantías en los procesos penales del Departamento del Huila. Análisis de su nivel de eficiencia y garantía (2007)
}

\author{
Semillero de Investigación Paideia \\ Adriana Solano Herrera, Ángela María Perdomo Carvajal, \\ Carlos Andrés Murillo Barrios, Jannifher Plazas Vargas, \\ María del Mar Méndez Bonilla, Yenny Lorena Montes Perdomo, \\ Yojanier Gómez Mesa, William Iván Rojas.
}

Docente Tutor: Helber Mauricio Sandoval Cumbe Grupo Nuevas Visiones del Derecho

Articulo recibido: 19/10/2008 Aprobado: 21/01/2009

\section{RESUMEN}

Partiendo de la necesaria situación de establecer un nuevo sistema que respondiera de manera real y efectiva a la crisis de justicia y la mora que se venía presentando en las causas criminales, se hizo necesaria la adopción del nuevo Sistema de Procedimiento Penal de corte acusatorio, en el cual se destaca el protagonismo de la figura del Juez con funciones de Control de Garantías, que asume la tarea de garante de los derechos fundamentales del investigado así como de las víctimas.

La dificil labor de lograr un equilibrio entre la realización de la justicia y la de asegurar la protección real de los derechos fundamentales de los sujetos procesales, es una responsabilidad que se evidenciará especialmente con el actuar de estos jueces. Ellos estarán sujetos entonces a la ponderación entre la persecución efectiva de las conductas delictivas, labor que representa el interés legítimo del Estado, y la salvaguarda de los derechos constitucionales que les asisten a quienes tienen la calidad de imputados, principalmente. Todo esto obliga a analizar cuál es la tendencia que en la práctica se mostrará con una mayor prevalencia respecto de estos dos puntos especialmente definitivos a la hora de evaluar la eficacia del SistemaProcesal Penal Acusatorio.

\section{PALABRASCLAVE}

Juez de control de garantías, eficiencia, garantía, derechos constitucionales, justicia.

\section{ABSTRACT}

Based on the situation needed to establish a new system to respond in a real and effective to the crisis of default, and the arrears that was being presented in the criminal reasons, it became necessary to adopt the new System of Criminal Procedure Accusatory cut in which will highlight the role of the figure of Judge guarantees control with responsibilities for controlling collateral, that figure assumes the task of becoming a guarantor of fundamental rights of the investigated and the victims. The difficult task of balancing the realization of justice and ensure the effective protection of fellow's to the proceeding fundamental rights is a responsibility that is particularly evident in the actions of these judges. These will be subject to the balance 
between the prosecution of criminal behavior, work that represents the legitimate interest of the state and safeguarding the constitutional rights of that people who are accused. All this has led us to analyze what is the trend in practice is shown with a higher prevalence regarding the two points mentioned above.

\section{KEYWORDS}

Judge guarantees control, efficient, guaranteed, constitutional rights, justice.

\section{INTRODUCCIÓN}

La transición del Sistema de enjuiciamiento penal Colombiano se hizo efectiva gracias a la entrada en vigencia de la Ley 906 del 2004, expedida en desarrollo del Acto Legislativo 03 del 2002, el cual trajo consigo un sistema de corte acusatorio, hoy aplicado en la mayor parte del territorio nacional, generando gran impacto, para algunos con consecuencias positivas y para otros tantos, bastante negativas. Dada su implementación gradual y por ámbitos territoriales, entro a regir en el departamento del Huila a partir del primero de enero del 2007.

Varios aspectos justificaron el cambio del sistema; entre ellos, el alto grado de impunidad, la ausencia de eficacia del sistema penal, la congestión permanente en los despachos, la lentitud de los procesos y el exceso de formalidades.

El presente artículo recoge los principales aspectos de la investigación desarrollada por el semillero de investigación "Observatorio Jurídico Penal PAIDEIA" de la facultad de Derecho de la Universidad Surcolombiana, cuyo tema de investigación, dentro del espectro de aquel nuevo sistema procesal penal, se ocupó de "El control de garantias en el departamento del Huila durante el año 2007, análisis de su nivel de eficacia $y$ garantia". Justificó el desarrollo de ésta investigación, lo novedoso de éste particular rol asignado al juez penal municipal del lugar de comisión de la posible conducta punible, dentro del proceso y ante todo, el impacto de esas funciones en el curso del mismo.

Con más de cuatrocientos años de historia en el país, el Sistema Penal con tendencia inquisitiva fue el modelo que con preferencia se aplicó, demostrando notorias incongruencias que con todo y su amplia perduración, encarnaba la afectación de valiosísimos principios como el de prevalencia del derecho sustancial, la contradicción, la inmediación de la prueba, la presunción de inocencia, la oralidad, la publicidad y ante todo la celeridad, convirtiendo así al derecho penal en un expiatonio y tardío método de impartir justicia.

Los necesarios cambios que requería el sistema de enjuiciamiento para entonces presente y a pesar de las significativas modificaciones que se le habian introducido, como la misma consagración de un órgano en el que se concentrara de manera objetiva la labor investigativa, no surtió los esperados efectos. La concesión de facultades judiciales hecha a la fiscalía que pasaron a confundirse con las investigativas, lo convirtieron en un órgano poderoso con capacidad para afectar discrecionalmente los derechos fundamentales de los investigados, agregando un ingrediente de confusión, práctica que acentuó mucho más las falencias del sistema. La imprescindible delimitación de funciones y roles, para cada uno de los actores e intervinientes en el proceso que de igual manera invocaban insistentemente un procedimiento ágil, oral, público y ante todo garantista, llevó a que se adoptara el procedimiento anglosajón y a través de la Ley 906 de 2004 -Código de Procedimiento Penal-, el desarrollo legislativo de los postulados acusatorios en la actuación penal. Dentro de las modificaciones logradas con éste nuevo sistema implantado, se crea la función de control de garantías que tiene por objeto el garantizar los derechos fundamentales principalmente del procesado, realizando el control judicial de la investigación para prevenir y corregir posibles irregulanidades. 
Esta novedosa función generó, "un cambio en la cultura del sistema judicial colombiano ya que pasamos de un sistema mixto a uno acusatorio. En aquel, el fiscal dirigía la investigación penal y tenía la potestad para privar de la libertad a un sindicado, es decir, era autónomo para proferir órdenes de captura y decretar la práctica de pruebas. La investigación penal desde la etapa preliminar hasta el cierre de la misma tenía el carácter de reservado y público en el juicio". (Academia Superior de Inteligencia y Seguridad Pública. 2006).

Como se observa, la aplicación práctica de este nuevo sistema de enjuiciamiento criminal trajo consigo reveladores cambios legales, judiciales, jurisprudenciales y sobre todo culturales en la historia jurídica colombiana, generando por consiguiente diversas controversias y comentarios para la justicia nacional.

Ante necesidad de verificar si efectivamente el nuevo sistema procesal penal acusatorio en el departamento del Huila alcance los objetivos para los cuales fue creado, en el marco de la función de control de garantias, se ha planteado el siguiente problema jurídico:

¿Cuál es el grado eficacia de la aplicación de la función de control de garantías en el Departamento del Huila, y cuáles han sido las condiciones para el desarrollo de la misma?

La investigación buscó a manera de objetivo general, analizar el control de garantías en los procesos penales iniciados en el año 2007 en el Departamento del Huila y determinar su grado de eficacia asi como el impacto que dicho control ha generado. A tal efecto, se buscó también, como objetivos específicos, el recopilar y analizar providencias proferidas por los jueces de control de garantías durante el año 2007 en los circuitos judiciales del Huila para identificar el nivel garantista en la aplicación del mismo. Al lado de ello, se pretendió también conocer las condiciones en que se está desarrollando la función de control de garantías.

Para lograr obtener resultados, se optó por desarrollar la investigación a través de un enfoque analítico descriptivo; la descripción, registro, análisis e interpretación con fundamento en la realidad local y departamental. El enfoque se hizo tanto desde la perspectiva cualitativa como cuantitativa. Se aplicaron entrevistas a jueces, fiscales y defensores de los circuitos del Departamento del Huila, además del análisis de las actas de la audiencia de control de garantías aplicadas durante el año 2007 en el mismo territorio realizadas por jueces que cumplen esta función.

\section{SISTEMAPENALACUSATORIO(LEY 906/04)}

La estructura organizacional de los entes administradores de justicia ha dado sobrada evidencia de su incapacidad para atender la necesidad de una pronta y cumplida justicia, resulta imperativo identificar en que aspectos radica su deficiencia e introducirles la reestructuración y que el diagnostico demande (Peña Venegas, J. 2001).

De acuerdo con la descripción del panorama hecha por el citado autor, se hacía entonces necesaria la implementación de un nuevo sistema que diera respuesta a aquellos requerimientos.

Así, como alternativa de solución definitiva a dichos problemas, el constituyente resolvió diseñar un nuevo sistema de enjuiciamiento criminal. Por ello, partir de la nueva Carta Política de 1991 y posteriormente con la expedición del Acto Legislativo número 3 de 2002 se separaron los roles del fiscal y del juez, dando al primero la obligación de perseguir el delito y al segundo la de defender los derechos de los investigados, de las víctimas y de la sociedad.

"El nuevo esquema de investigación y juzgamiento criminal adoptado en Colombia tiene las siguientes características:

1. La realización de la investigación tiene como director al fiscal y como ejecutor a la policía judicial, mientras que la tramitación del juicio oral se encuentra bajo la dirección del juez. 
2. Las potestades que antes se reconocían a la fiscalía para restringir los derechos fundamentales, especialmente la libertad, desaparecen de suámbito de acción.

3. Como consecuencia de lo anterior, los jueces adquieren un papel protagónico y determinante para el funcionamiento del nuevo sistema, destacando dentro del mismo el que se trata justamente de atribuciones que le corresponde cumplir a los jueces de control de garantías.

4. Cambia el papel del abogado dentro del proceso, ya que de emplear el conocimiento de las normas y leyes para el ejercicio de la defensa, pasa a requerir el dominio adecuado tanto de las reglas del procedimiento como de la prueba, ello implica que el buen abogado ya no será el que dilate los términos para forzar libertades y propiciar prescripciones, sino el que frente a las evidencias recomiende el mejor acuerdo y la mejor negociación.

5. A medida que la verdad surge del proceso dialéctico de la confrontación entre las partes, el proceso deja de servir para construir responsables y se convierte en el medio para descubrilos. En otras palabras, ya no se podrá capturar para luego investigar sino que primero se tendrá que investigar para luego sí poder capturar.

6. Aunque el juicio no es una competencia de oratoria, el propósito de la presentación se puede echar a perder por la carencia de un libreto adecuado, tanto para el acusador como para la defensa.

7. El proceso penal inscrito dentro del sistema acusatorio implica jueces conocedores de la técnica que sepan aplicar los principios y fiscales conocedores del los principios con un manejo idóneo de la técnica.

8. Finalmente, la estructura del proceso penal dentro del nuevo sistema implica la adopción entre otras, de los principios de publicidad y oralidad, cuya cabal aplicación será determinante para asegurar su implantación exitosa". (Restrepo Medina, M. 2005).

"El proceso penal se desarrolla en etapas definidas:

* Indagación (ante la Fiscalía y con la policía, es la etapa de averiguación, en donde eventualmente se acude al juez de control de garantias para que autorice ciertas diligencias).

* Investigación propiamente dicha, delimitación del delito e identificación del sujeto activo (ante el juez de control de garantías con la imputación)

* Juicio oral y público (ante el juez de conocimiento competente).

Es así como se observa que las funciones de los jueces están claramente delimitadas entre la función de control de garantías (cuyas misiones son las de controlar el abuso de poder y proteger los derechos $y$, en consecuencia, evitar las restricciones arbitranias de los derechos) y la de conocimiento que estudia la responsabilidad penal de los imputados". (Consejo superior de la judicatura 2005).

Además, jurisprudencialmente se ha resaltado que "las finalidades perseguidas con la reforma constitucional fueron: (i) fortalecer la función investigativa de la Fiscalia General de la Nación, en el sentido de concentrar los esfuerzos de ésta en el recaudo de la prueba; (ii) la configuración de un juicio público, oral, contradictorio y concentrado; (iii) instituir una clara distinción entre los funcionarios encargados de investigar, acusar y juzgar; (iv) descongestionar los despachos judiciales mediante la supresión de un sistema procesal basado en la escritura para pasar a la oralidad, y de esta forma, garantizar el derecho a ser juzgado sin dilaciones injustificadas; (v) modificar el principio de permanencia de la prueba por aquel de la producción de la misma durante el juicio oral; (vi) introducir el principio de oportunidad; (vii) crear la figura del juez de control de garantías; e (viii) implementar gradualmente el nuevo sistema acusatorio.

Con respecto a los actores que intervienen en la 
relación jurídica y en el proceso penal, se resalta que el nuevo esquema constitucional prevé la intervención (a) del imputado, (b) del Fiscal, (c) del Juez de conocimiento de la causa, (d) del Ministerio Público a través de la Procuraduría General de la Nación, (e) del juez de control de garantías, y (f) de los jurados, encargados ahora de administrar justicia en forma transitoria en los términos que señale la ley. Así mismo, el Acto Legislativo faculta al Legislador para fijar los términos precisos en los cuales (g) las víctimas del delito habrán de intervenir en el proceso penal". (Sentencia C-718 de 23 de agosto de 2006, M.P Dr. Álvaro Tafur Galvis).

Los derechos y las garantías Constitucionales en el nuevo sistema penal son principalmente:

\section{$\checkmark$ Derechoa la tutela efectiva:}

Derecho fundamental de toda persona a acceder a la administración de justicia en espera de una respuesta efectiva dada en un plazo razonable, debidamente motivada y recurrible, en condiciones de igualdad y seguridad jurídica.

\section{$\checkmark$ Derecho fundamental a la libertad:}

La libertad personal es el estado físico o corporal de una persona en el espacio, que depende de su autodeterminación y no de obligación externa de permanecer en un lugar determinado, situación libre de medidas coercitivas como la captura, la detención o la prisión. Algunos derechos intimamente relacionados con la libertad son el habeas corpus, la intimidad yla dignidad humana.

\section{$\checkmark$ Derecho fundamental a la no autoincriminación:}

El derecho que toda persona imputada tiene de abstenerse de acudir a declarar ante órgano de investigación o juzgamiento y, en el caso de renunciar a ese privilegio de manera consciente, voluntaria y asesorada, de no "...declarar contra sí mismo..." (Art. 33 Código Penal) guardando silencio. También ejerce tal derecho la persona que, sin ser imputada, acude a declarar ante órgano judicial y guarda silencio frente a eventuales preguntas que puedan afectar su responsabilidad penal.

\section{Derecho fundamental al debido proceso:}

Comprende las garantías constitucionales que debe reunir todo proceso penal para asegurar al imputado la certeza, la justicia y la legitimidad de su juzgamiento, desde el inicio del proceso, pasando por los actos de investigación, sus controles judiciales, la actividad preparatoria y probatoria, las distintas audiencias públicas, los mecanismos de impugnación, el respeto de los términos procesales, hasta la obtención de un fallo basado en la prueba yen la justicia del caso.

Las garantías sustanciales del debido proceso comprenden: el principio de legalidad, el principio de favorabilidad, presunción de inocencia (in dubio pro reo), derecho de defensa y la garantía de prevalencia del derecho sustancial. Las garantías procesales comprenden: el principio acusatorio, el juez natural, el principio de celeridad, el derecho a los recursos, el principio de inmediación de la prueba, el principio de contradicción, el principio de concentración yel principio de oralidad.

Por último, las garantías orgánicas son: la imparcialidad, la independencia y la responsabilidad del juez.

El sistema penal acusatorio brinda la oportunidad de hacer de nuestras sociedades espacios de convivencia y justicia dignos, siempre en busca de los bienes y valores fundamentales que posibilitan un mínimo vital, acercándonos más a la construcción de un tejido social capaz de irradiar en cada persona, valores y significado con profundas bases democráticas, participativas y pluralistas". (Jiménez Montes, F. 2008).

\section{JUEZ CON FUNCIONES DE CONTROL DE GARANTÍAS}

Uno de los aspectos esenciales del Sistema Penal Acusatorio se ve materializado en la novedosa figura del juez con funciones de control de garantías, caracterizado por su imparcialidad e 
independencia; se trata de aquella persona a quien le corresponde ejercer el control de legalidad, tanto formal como material, sobre las actuaciones que adelanta la fiscalía a través de la policía judicial, ya sea previo 0 posterior a aquellas, buscando verificar la legalidad procesal que se logra con el efectivo goce de los derechos fundamentales. Este control judicial a las medidas restrictivas de los derechos fundamentales garantiza la plenitud del nuevo sistema porque desarrolla el material axiológico constitucional, como el principio de legalidad que hace parte del núcleo esencial del derecho fundamental al debido proceso.

"Se satisfacen asi dos presupuestos centrales de un proceso penal garante del debido proceso: reserva judicial de la limitación de derechos fundamentales y control sobre las actuaciones estatales". (Bernal, J. y Montealegre, E. 2004).

Particular mención se ha hecho en la jurisprudencia al reiterar que en el nuevo sistema procesal penal, una sustancial novedad fue:

La creación de la función del juez de control de garantías, con competencias para adelantar "(i) un control sobre la aplicación del principio de oportunidad; (ii) un control posterior sobre las capturas realizadas por la Fiscalía General de la Nación; (iii) un control posterior sobre las medidas de registro, allanamiento, incautación e interceptación de llamadas; (iv) un control previo para la adopción de medidas restrictivas de la libertad y (v) decretar medidas cautelares sobre bienes; (vi) igualmente deberá autorizar cualquier medida adicional que implique afectación de derechos fundamentales y que no tenga una autorización expresa en la Constitución. De tal suerte que el juez de control de garantías examinará si las medidas de intervención en el ejercicio de los derechos fundamentales, practicada por la Fiscalía General de la Nación, no sólo se adecúan a la ley, sino si son o no proporcionales, es decir, (i) si la medida de intervención en el ejercicio del derecho fundamental es adecuada para contribuir a la obtención de un fin constitucionalmente legítimo; (ii) si la medida es necesaria por ser la más benigna entre otras posibles para alcanzar el fin; y (iii) si el objetivo perseguido con la intervención compensa los sacrificios que esta comporta para los titulares del derecho y la sociedad". (Sentencia C-718 de 23 de agosto de 2006, M.P Dr. Álvaro Tafur Galvis).

Es importante tener claro que ahora, con el nuevo sistema, la afectación de la libertad por medida de aseguramiento no estará a cargo de fiscales, sino de jueces con funciones de control de garantías, ya que ante ellos los fiscales deberán solicitar la medida cautelar de privación de libertad, siendo esta una garantía fundamental de protección a la libertad individual de personas vinculadas al proceso penal.

Si bien el articulo 116 C.N. incluye a la Fiscalía General de la Nación dentro de las autoridades que administran justicia, esta entidad no tiene una competencia general para afectar derechos fundamentales y dicha prerrogativa se reduce a dos hipótesis: a) Los casos taxativamente previstos en la Carta (nums. 1 y 2 art.250), como son la captura excepcional, registros, allanamientos, incautaciones e interceptación de comunicaciones,

y b) Las afectaciones leves de derechos fundamentales, oniginadas en el aseguramiento de los elementos materiales probatorios (num. 3 art. 250 C.N.) (Bernal, Jy Montealegre, E. 2004).

De esta manera se afirma, que la tan importante actuación del juez con funciones de control de garantías logra legitimar el sistema porque se erige como el garante de uno de los derechos fundamentales de mayor relevancia dentro un Estado Social de Derecho como el colombiano, en el que la restricción a la libertad es una excepción y no una regla como lo era para el sistema anterior, valga decirlo, de corte inquisitivo.

En ese mismo sentido, "conforme al numeral 1 artículo 250 C.N., el juez de control de garantias es el encargado de adoptar medidas de aseguramiento y protección a la comunidad y las victimas. Sobre este punto, es de anotar que las medidas de aseguramiento dingidas a garantizar la comparecencia de los imputados son una función ordinaria del juez de control de garantías, porque la constitución establece el carácter excepcional de la 
autorización, previa ley de la República, para que la Fiscalia adopte y realice capturas". (Bernal, Jy Montealegre, E. 2004).

La Corte Constitucional ha reiterado que la salvaguarda de los derechos fundamentales del investigado es función prioritaria adscrita al juez de control de garantías. Así, toda actuación que involucre afectación de derechos fundamentales demanda para su convalidación, el sometimiento a una valoración judicial, con miras a garantizar el necesario equilibrio que debe existir entre la eficacia y la funcionalidad de la administración de la justicia penal y los derechos fundamentales del investigado.

En resumen, dentro del nuevo sistema penal acusatorio, los jueces con funciones de control de garantías son los responsables de inspeccionar que las actuaciones que se surtan dentro del proceso de investigación por parte de la Policía Judicial y la Fiscalía, que afecten los derechos de las personas investigadas, se lleven a cabo siguiendo los parámetros legales.

La verificación del cumplimiento de todos los fines que normativamente se han señalado para el alcance pleno y la superación de todas aquellas problemáticas que habían quedado como consecuencia de la larga existencia del Sistema inquisitivo y las condiciones en que se halla el desarrollo del nuevo sistema de enjuiciamiento condujoa los siguientes:

\section{RESULTADOS DE LA INVESTIGACIÓN EN EL DEPARTAMENTO DEL HUILA}

Durante el proceso de adaptación que se ha venido desarrollando en el Departamento del Huilaa raíz de la implementación del Nuevo Sistema de Procedimiento Penal Acusatorio, se establecieron una serie de aspectos que permiten delinear el panorama del estado en que se encuentra y su marco de acción. Las diversas dificultades que sufre y ha sufrido la implementación de este nuevo modelo de juzgamiento en la legislación han surgido, en principio, porque al ser un modelo de conformación foránea, no ha tenido una adaptabilidad pasible, resultando en veces notoria la falta de correspondencia con las necesidades propias de la realidad social y jurídica. Los vacíos que en la práctica se han suscitado son complementados por la junisprudencia de las altas Cortes, lo que conlleva a que los desarrollos interpretativos sean inestables o tiendan a ser más confusos que las mismas normas, generando inseguridad jurídica. Prueba de ello son los siguientes datos estadísticos que fueron obtenidos a partir de la aplicación de las entrevistas a jueces, fiscales y defensores y el análisis de las actas proferidas en las audiencias de control de garantías.

Los diferentes actores judiciales del Departamento, han apreciado particularmente que el gran reto de alcanzar la plenitud del sistema desde el principio de su aplicación se ha visto socavado. Los diferentes actores de los circuitos del departamento del Huila se hallan aun en un proceso de formación y capacitación respecto a todo el amplio universo de conocimientos que implica este nuevo sistema, tanto en sus aspectos teóricos como prácticos.

Uno de los retos inmediatos que enfrentan los diversos actores judiciales con este nuevo sistema ha sido la insuficiencia normativa; para los jueces, fiscales e incluso defensores públicos los vacíos que se han evidenciado, han sido decantados porla poca jurisprudencia que no llena las expectativas, aun existen vacíos y deficiencias en cuanto al sistema como tal, en su estructura y práctica, y en relación a los sujetos intervinientes, además, se ha legislado, tratando de hacer encuadrar el Sistema Procesal Penal Acusatorio a la realidad, basándose en estructuras absolutamente inconsistentes con él mismo, lo que conlleva a desdibujarlo antes que llenar vacíos o resolver falencias. 
¿Considera que la regulación normativa que se ha venido expidiendo sobre la materia resuelve vacios que en su práctica se han evidenciado?

Gráfica 1

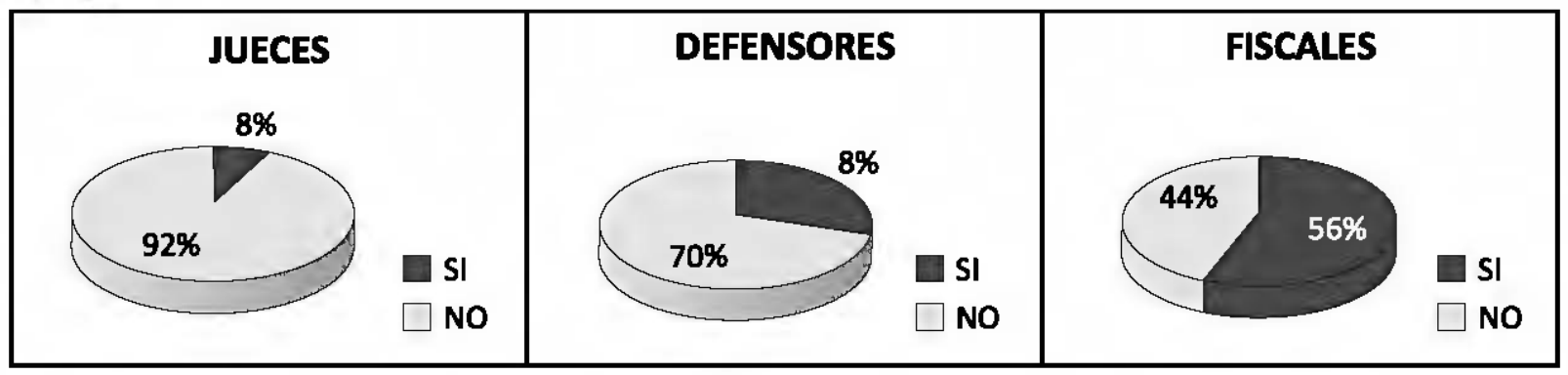

De igual forma los diferentes intervinientes en el proceso penal orientado por el Sistema Acusatorio, de acuerdo con los resultados de la investigación, no están suficientemente preparados para asumirlo y aplicarlo en su integridad. En la práctica, las actuaciones hablan por sí solas. Para los jueces, esto se evidencia en especial con los abogados litigantes que no tienen suficiente conocimiento del sistema. Para la defensoría es mayoritaria la apreciación de la falta de preparación de los diferentes intervinientes. En efecto, con los fiscales sucede lo mismo, porque aunque algunos se han preparado en el Sistema, muchos de ellos no tienen la habilidad de la expresión, cualidad esencial para actuar debidamente dentro del sistema ya que se cambia el mismo pero no de mentalidad y cultura. Todo se improvisa, es un sistema que demanda muchos elementos que parecen no estar en el entorno ni en la capacidad de los actores judiciales. Sin embargo, es de destacar que la capacitación ha sido un tema que les preocupa, y se ha tratado constantemente dentro de la misma institución.

Por supuesto existen puntos positivos con la implementación del nuevo Sistema Procesal Penal Acusatorio, para los jueces y fiscales se está garantizando el ejercicio eficaz del derecho a la tutela judicial efectiva de quienes intervienen en el proceso penal, puesto que siempre se respetan los derechos fundamentales. De igual manera a las víctimas se les considera sujetos procesales, es decir, también tienen garantías; se le ha dado una relativa agilidad, inmediatez y eficacia; sin embargo, es mucho más efectiva para situaciones de flagrancia que se resuelven de manera inmediata, contranio a los demás casos (denuncia, petición especial, querella) que se evacuan de acuerdo al tumo de llegada.

"Es de destacar que el garantismo y el mal llamado "eficientísimo" no son concepciones antagónicas ni excluyentes entre sí, sino paralelas y "gemelas", amabas imperativas, convergentes, para que se ejercite apropiadamente la acción penal, dentro de la debida observancia de las garantías constitucionales. En tal medida la actuación procesal debe desarrollarse "teniendo en cuenta el respeto de los derechos fundamentales de las personas que intervienen en ella y la necesidad de lograr la eficacia del ejercicio de la justicia", haciendo que prevalezca el derecho sustancial, como bien ordena el artículo 10 de la ley 906 de 2004". (Ramírez Bastidas, 2005).

Por el contrario, para los defensores, las garantías de las víctimas, se han relativizado porque según ellos priman las del imputado y las fallas en el procedimiento del ente acusador producto de la falta de preparación, las cuales no permiten alcanzar la última etapa, el juicio oral, en muchos de los hechos punibles.

Ahora bien frente a otro de los aspectos que se buscaba resolver con la implementación de este nuevo sistema como fue el de la impunidad, se tiene que desde la percepción de los jueces aún no se puede afirmar que con el Nuevo Sistema, se logre contrarrestar la impunidad; sin embargo, hay que 
destacar que pese a ser tan garantista, aún se presentan casos de vulneración a derechos fundamentales del investigado y las víctimas, lo que trae consigo impunidad situación que se aprecia con un $16 \%$ de los procedimientos decretados ilegales, datos obtenidos en la investigación. Igualmente para los defensores, el desarrollo del sistema no está cumpliendo con uno de sus fines como es el de reducir los altos índices de impunidad. Para los fiscales este nuevo sistema es una herramienta, que no logra con plenitud contrarrestar esta evidente problemática, no se cuenta con los elementos suficientes aunque este sea garante, aún hay congestión judicial, no hay responsabilidad social; lo que tiende a concluir que la impunidad se ha agravado. Se reitera que es efectiva en las capturas en flagrancia, porque en cuanto a las situaciones que requieren denuncia, la ciudadanía no ejerce la acción, sea por temor $u$ otras circunstancias, como retaliaciones por parte de aquellos que delinquen, lo que convierte la labor de las autoridades en infructuosas.

¿Considera usted que el nuevo Sistema Procesal Penal Acusatorio constituye un instrumento efectivo para contrarrestar la impunidad?

Gráfica 2

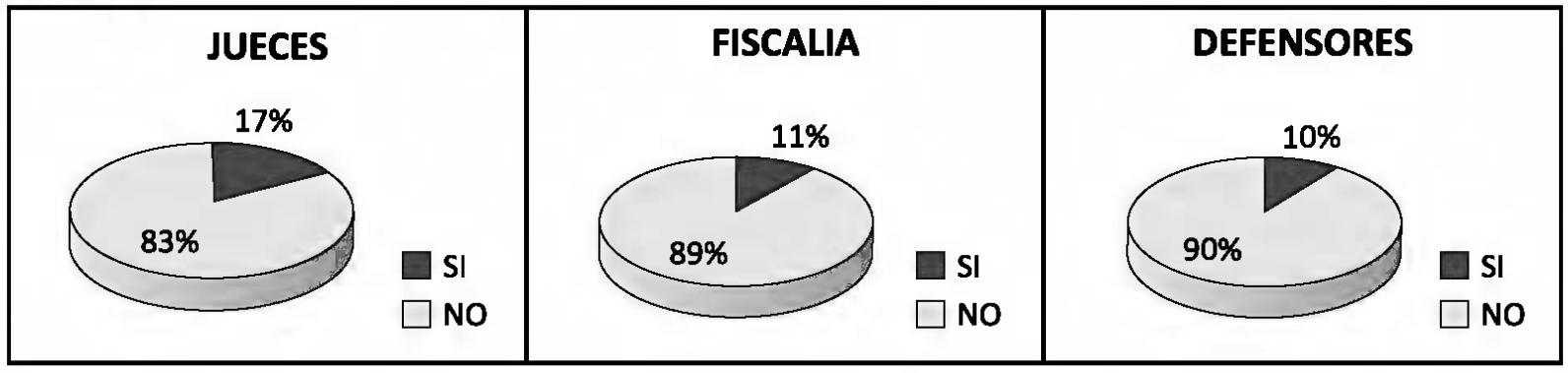

De acuerdo con las características del sistema y su diseño para los jueces de los diferentes circuitos judiciales de Huila, el juez con funciones de control de garantías es un sujeto novedoso, no existía tal figura con estas calidades y facultades, como la defensa y salvaguarda de los derechos fundamentales del indiciado y las víctimas; aquél, ya no maneja pruebas, tan solo verifica que todas la actuaciones se ajusten a los parámetros del Bloque de Constitucionalidad, la Constitución y la Ley. Para los fiscales, aunque las garantías constitucionales ya se encontraban consagradas, la figura del juez con funciones de control de garantías, entra a jugar un papel determinante en la materialización de las mismas, porque controla los actos de investigación, lo cual antes no existía puesto que las órdenes eran proferidas directamente por la misma Fiscalía. Además, en el Nuevo Sistema Penal Acusatorio, se le ha considerado como la única autoridad facultada para tomar decisiones relacionadas con los derechos fundamentales del indiciado y las víctimas. Para los defensores, la figura protagónica del juez con función de control de garantías es esencial puesto que, sin perjuicio de la interposición y ejercicio de las acciones de tutela cuando sea del caso, como quiera a su cargo esta examinar si las facultades judiciales ejercidas por la Fiscalía se adecuan o no a sus fundamentos constitucionales $y$, en particular, si su despliegue ha respetado o no los derechos fundamentales. 
¿Cree que en la práctica se ha asumido correctamente el sentido para las cuales fueron creadas estas funciones de control de garantías?

Gráfica 3

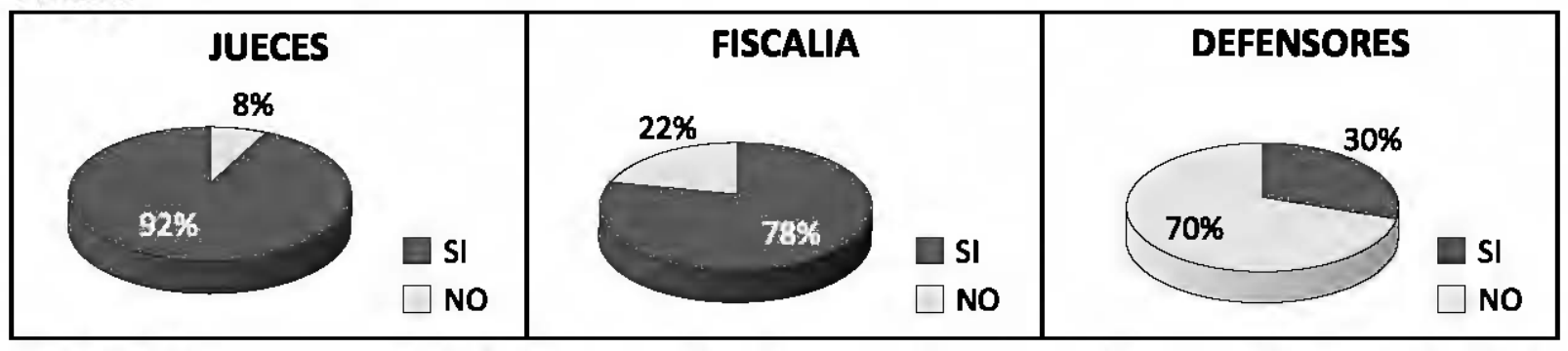

Y es que en la práctica, la labor de los Jueces con Funciones de Control de Garantías se ha asumido correctamente, porque es de alto nivel, es decir, legitima el Sistema Procesal Penal Acusatorio al salvaguardar las garantías constitucionales del investigado y las víctimas; sin embargo, se debe hacer mención al hecho de que su competencia se ha involucrado con asuntos civiles (bienes incautados durante la investigación, entrega de vehículo...) lo que desvía un poco su especialidad. Hay que tener en cuenta que aún el sistema se encuentra en construcción. Los fiscales han apreciado en la práctica, que la labor de los Jueces con Funciones de Control de Garantías se ha cumplido correctamente, porque su presencia garantiza el respeto de las garantías constitucionales en todas la actuaciones y diligencias dentro del proceso penal, lo cual se ajusta con lo que demanda la nueva Ley de Procedimiento Penal. Sin embargo, algunos de ellos disienten de esta postura porque consideran que en ciertos casos es demasiado garantista, lo que puede dificultar la labor investigativa o en el peor de los casos, llegar al extremo de reclamar frente a un control inexistente. Por el contranio, para los defensores, en la práctica no se ha asumido correctamente el sentido para el cual fueron creadas estas funciones de control de garantías, puesto que no se ha dado una integralidad y porque los criterios de los jueces que se manejaban en el sistema mixto eran distintos.

De las audiencias realizadas por los jueces de control de garantias en su primer año de implementación en el departamento del Huila, se determina que si bien los procedimientos de captura en flagrancia, en su mayoría fueron decretados legales, respecto al volumen de los decretados ilegales se puede afirmar que dicha situación se debe a la insuficiente preparación por parte de la policía judicial y la fiscalía en cuanto al nuevo sistema y su desarrollo práctico; situaciones como el no tener en cuenta la importancia de comunicar los derechos del capturado y el término para realizar la audiencia de legalización de captura (dentro de las 36 horas siguientes a la actuación), son los factores que más comúnmente se presentan. De los procedimientos de captura con orden judicial es evidente el control de legalidad más exhaustivo manifestado en el poco número de actuaciones ilegales que resultan de la existencia de un error ostensible en la valoración de los medios probatorios que tiene en cuenta la Fiscalía para solicitar la medida de aseguramiento, por lo que el Juez de control de garantías opta por cancelar las ordenes de captura ya impartidas. De igual manera, y como se mencionó anteriormente, el juez con función de control de garantías se debe pronunciar acerca de las medidas cautelares sobre bienes, las cuales son aplicadas simultáneamente en una misma audiencia de legalización de captura y formulación de imputación, en las comúnmente llamadas audiencias de "combos" las cuales se "aplican sobre los bienes o recursos que han sido utilizados como medio o instrumento de un delito doloso o en otros eventos se relacionan con el ejercicio del incidente de reparación integral". Manual para el juez de control de garantías en el sistema acusatorio penal. Extraído 15 de junio de 2009 desde: http://www.ramajudicial.gov.co/csj_ portal/assets/020-. Es asi como el Juez de Control de Garantías también se encarga de salvaguardar los derechos de las víctimas. 


\section{Gráfica 4}

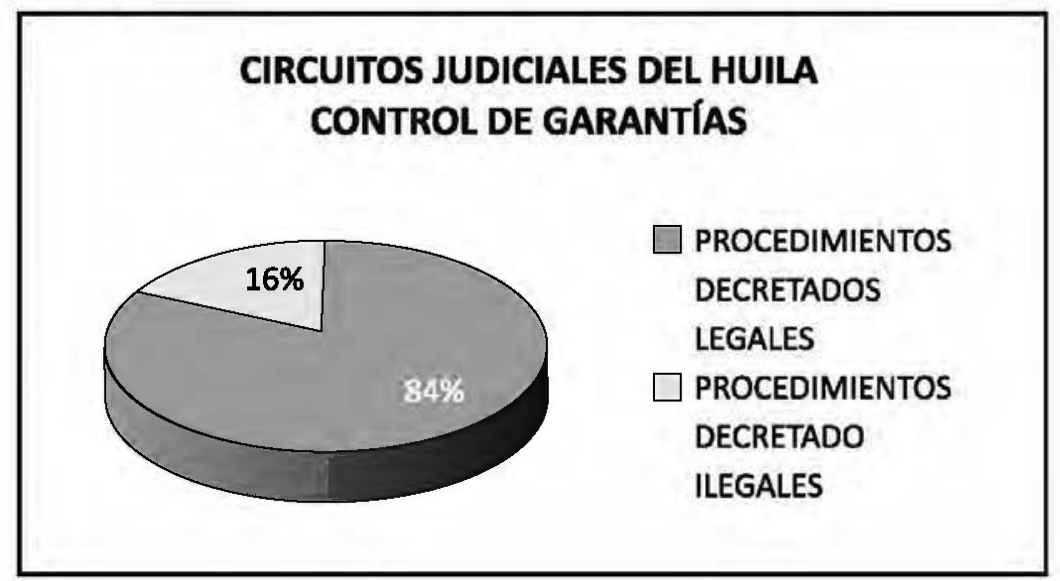

Sin lugar a dudas, la implementación del nuevo sistema penal acusatorio -Ley 906 de 2004trae consigo una reestructuración del modelo de justicia penal colombiano que determina el marco axiológico y los principios básicos que garantizan un debido proceso, tales como el principio de legalidad, favorabilidad, presunción de inocencia, derecho de defensa, celeridad, inmediación, concentración y contradicción de la prueba, publicidad y oralidad, permitiendo así la introducción de la figura del juez del control de garantías como la primera instancia en el control de legalidad de todas las actuaciones que impliquen afectación de los derechos fundamentales; empero lo anterior, en la práctica del Departamento no se ha logrado materializar de manera eficaz los fines del mismo, al no contar con los recursos humanos, financieros, de infraestructura que dicho sistema acusatorio demanda, situación que aún persiste ya que ha sido destacado en anteriores investigaciones que "al encontrar que se previó como segunda medida en eficacia para resolver la problemática de la justicia, organizar y dotar adecuadamente los despachos judiciales" (Vélez E, Gómez Py Giraldo J. 1987).

Como corolario de lo analizado, se concluye:

- La figura del juez con función de control de garantías ha logrado cumplir el fin para el cual fue creado, aun dentro de sus limitaciones, sus actuaciones han sido la muestra de que la prevalencia de los derechos fundamentales. Lo anterior se puede asegurar al analizar cuantitati- vamente en los procedimientos decretados legales e ilegales.

- La tendencia garantista es la que ha mostrado una prevalencia respecto de la eficiencia, porque la labor de control de legalidad de las diligencias que implican afectaciones a derechos fundamentales que adelanta el juez, ha sido protagónica.

- La eficacia en la función de control de garantías no se logra alcanzar aun, puesto que las condiciones externas (falta de personal capacitado, infraestructura, desarrollo legislativo) imposibilitan que el sistema, y quienes lo desarrollan lo ejecuten y respondan en la misma proporcionalidad en que se requiere.

- La falta de preparación y el insuficiente número de agentes de policía judicial con el que cuenta la fiscalía se configura como una de las problemáticas más significativas en el desarrollo de su labor, lo cual se ha visto reflejado en los pronunciamientos que han proferido los jueces de control de garantías.

- La tendencia garantista se mantiene tanto en las actuaciones que se decretan ilegales porque se han debido garantizar los derechos del indiciado o imputados frente a las acciones que producto de un juicio de proporcionalidad, han rebasado los limites legales a los cuales se debe ceñir la fiscalía, así como para las actuaciones que se ha decretado legales por cumplir satisfactoriamente con los presupuestos facticos y de derecho señalados para el desarrollo de tales. 
- La garantía y la eficiencia solo se lograrán paralelamente en la medida en se obtenga la complementaniedad física y juríica, situaciones necesarias para la implementación y el sostenimiento de estas dos tendencias.

\section{BIBLIOGRAFÍA}

- Academia superior de inteligencia y segunidad pública, Fondo rotatorio del departamento administrativo de seguridad- DAS, (2006). Sistema penal acusatorio. Rol del perito y de la policía judicial. Bogotá. Universidad Nacional de Colombia. Convenio interadministrativo de cooperación académica de extensión. Primera edición.

- Aponte Cardona Alejandro, (2006). Manual para el juez de control de garantías en el sistema acusatorio penal. Bogotá. Consejo Superior de la Judicatura Sala administrativa. $2^{\mathrm{a}}$ edición, de http://www.ramajudicial.gov.co/csj_portal/assets/020-Manual\%20Juez\%20de\%20Garantias-SPA.pdf

- Bemal Cuéllar Jaime, Montealegre Lynett Eduardo, (2004). El proceso penal, fundamentos constitucionales de nuevo sistema acusatorio. Bogotá. Universidad Externado de Colombia.

- Corporación excelencia de la justicia, (2004). Nuevo código de procedimiento penal ley 906 de 2004 (sistema acusatorio). Bogotá. Editorial Corporación excelencia de la justicia.

- Consejo Superior de la Judicatura Sala Administrativa, (2005). Los cien primeros días del Sistema PenalAcusatorio. Bogotá.

- Jiménez Montes Fernando, (2008). Fundamentos Constitucionales. Unid I: "derechos y garantías constitucionales".

- Peña Venegas Jaime, (2001). El derecho de defensa en el proceso penal colombiano. Bogotá Ediciones doctrinayley.

- Ramírez Bastidas Yesid, (2005). Sistema acusatorio Colombiano. Bogotá. Ediciones doctrina y ley Ltda.

- República de Colombia. Diario oficial No. 45.645, de 19 de agosto. Decreto 2636 de 2004.

- Restrepo Medina Manuel, (2005). El nuevo sistema penal acusatorio. Bogotá. Círculo de lectores.

- Vélez Eduardo, Gómez Patricia y Giraldo Jaime, (1987). Jueces y justicia en Colombia. Bogotá Instituto de investigación SER.

\section{Sentencia}

- República de Colombia. Corte Constitucional. Sentencia C-718 de 23 de Agosto Del 2006. M.P. Dr. Álvaro Tafur Galvis. Expediente D-6055 